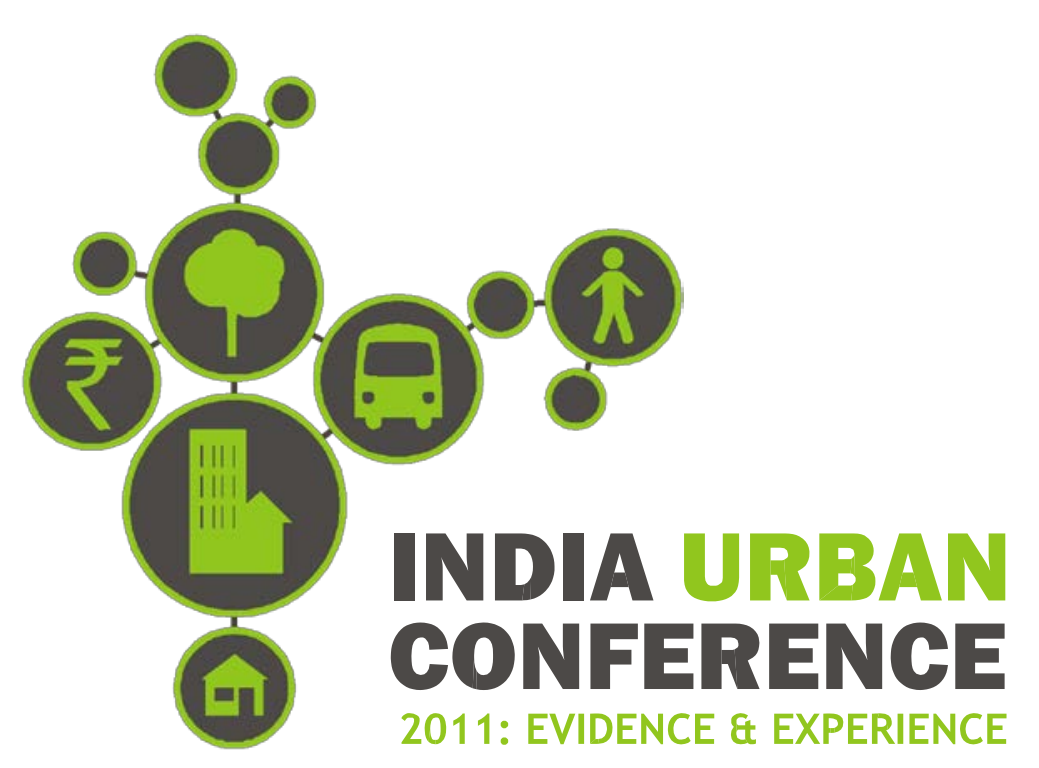

\title{
Land, Infrastructure and Ecological Sustainability in Indian Cities
}

A Background Paper for 'Infrastructure and Sustainability' India Urban Conference

Mysore, 17 November, 2011

Kavita Wankhade and Krishnachandran Balakrishnan 



\begin{abstract}
Land is one of the most contested and valuable of natural resources in urban areas. While many of the contestations may be primarily due to its economic value as territory, land is far more than the observable space. Land is an integral part of the urban ecological fabric and is closely linked to the dynamics of other resources like water and energy. The relationship between the nature and intensity of land-use, resource consumption and ecosystem functioning is of critical significance for urban sustainability. Urban spatial patterns which are mostly a result of planning paradigms and decisions, land availability and transportation choices can significantly influence urban resource consumption. This paper first examines broader issues around land, focusing specifically on land cover, land use, and densities, and then examines the inter-linkages between land and the infrastructure sectors of water, energy, and transport. The paper examines the current literature on Indian cities as well as some key international articles, focusing in particular on identifying the knowledge gaps and next steps for research, practice and policy in this domain.
\end{abstract}

\section{Introduction}

Land is an important part of the urban ecological fabric and is closely linked to the dynamics of other natural resources like water and energy. The relationship between the nature and intensity of land-use, resource consumption patterns and ecosystem functioning is of critical significance for urban sustainability. Urban spatial patterns which are mostly a result of planning paradigms and decisions, land availability and transportation choices can significantly influence urban resource consumption The intention of the background paper and panel is to initiate examination of the inter-linkages between urban spatial patterns, infrastructure and sustainability, and begin to set a research and practice agenda around this critical area. It specifically examines the intersection of land with water, energy and transport.

The growth of urban centres and the associated changes in land use and land cover can have multiple direct and indirect ecological impacts. These include creation of urban heat islands, fragmentation of ecological patches, and alteration of hydrological systems among others. While actual increase in urban land cover may be relatively insignificant in comparison to the extent of productive land and forest cover, the indirect impacts of such urban expansion and the nature of urbanisation, can be quite far-reaching due to extensive extraction of water, energy and material resources from the hinterland for the construction and operation of these cities. The resource intensity of cities is in turn dependent to a large extent on urban spatial patterns which in turn are often influenced significantly by urban planning paradigms and transportation choices.

In this context, it is critical to understand the changing patterns of land cover, land use and urban morphology in Indian cities, and also unearth the driving forces behind these particular patterns. As our literature review shows, while there is a growing body of work on resource use and ecological sustainability in Indian cities, land is often missing as an integrative element. Even as work is carried out on the sustainability implications of transport, energy and water infrastructure, the connection with land is weakly understood. This is problematic because land is a base resource in any city, and land-use and land cover have the potential to influence other patterns of resource use.
Moreover, since the studies are often sectoral, they do not explore inter-linkages across them. This paper and panel have been conceptualised with the intention of addressing this knowledge gap and identifying the next steps for research, practice and policy in this domain.

The paper is divided into four sub-sections: the first examines broader issues around land, focusing specifically on land cover, land use, and densities, while the next two sections examine two key resources: water and energy, and their intersections with land. In these two sections, water and energy are dealt with primarily as resources, while also examining the sustainability implications of infrastructure choices in these sectors.

The last section examines the significance of transportation infrastructure to urban sustainability. In each of the last three sections, the paper summarises the current status/ scenario in Indian cities and discusses the critical issues identified so far. The sections then focus on examining the intersection of each of these resources/ infrastructure with land through a review of available literature on Indian cities. However, since in most cases, this literature is limited, the paper will also review some key international articles to identify some of the knowledge gaps in relation to Indian cities. The sections also briefly examine current policy practice responses to urban sustainability concerns, and identifies some critical gaps.

Key research questions that have been identified are listed at the end of the paper in order to help structure the discussion by the panelists. The panel is designed in large part to be a mechanism for identifying significant gaps in current research, practice and policy with respect to land and environmental sustainability as applicable to Indian cities, and to help prioritise these issues. The panel will also discuss how concerns of ecological impacts, specifically related to land and land use, can be taken on board in the creation, planning and development of key infrastructure.

\section{Land Cover, Land Use and Urban Form}

Change in land cover, and modifications of land use account for one of the most significant changes in the environment due to human activity (Lambin, 1999). These changes on Earth's surface have pervasive effects on ecological systems. At the global scale, these changes have led to changes in carbon cycles and contributed to global warming and loss of biodiversity. At the regional scale, the changes have led to change in surface energy and water balance, and have also affected local climate. At a local scale, these have led to degradation of soil, alteration of bio-geochemical cycles and hence ecosystem services. Moreover, the changes have significantly affected the hydrological cycles by disrupting aquifers, and anthropogenic nutrient inputs into the soil (Foley, 2005; Lambin, 2001). In some cases, these changes have also adversely affected public health, and led to outbreaks of infectious disease. (Lambin, 2003)

At first glance, the issue of land and land use might appear superfluous to urbanisation as urban areas occupy less than 3 per cent of the total land area globally (Lambin, 2001),

but the issue is extremely important for a number of reasons. It is well documented that the impact of contemporary patterns of urbanisation on land and other resources far exceeds the actual extent of urban areas, as measured through ecological footprints and other tools. These second order impacts of urbanisation are strongly influenced by the actual extent and pattern of urbanisation. Moreover, there is already an indication that 
we may not be using land as efficiently as earlier, as the change in urban land use is faster than the rate of change in the urban population (Seto, 2010). Also, in almost all developing cities, the demand for urban land gets precedence over all other uses, and results in the loss of fertile croplands and ecologically sensitive areas (Lambin, 2003)

Even as land cover changes can result in high second order impacts, there are deleterious impacts at the local and regional scale too. The large urban agglomerations, and their peripheries, can lead to patch fragmentation and disrupt ecosystem services. The location of urban areas (coastal, hilly, riverine) also affects their environment impacts. One of the largest impacts of urban areas is on hydrological systems, through the ingress of pollutants in both surface water bodies, and underground aquifers, by disruption of aquifers, surface and underground water channels, and the 'reclamation' of land. Urban areas are also responsible for changes in bio-geochemical cycles. Land use changes, and construction of built up area also lead to urban heat island affects at the local level. (Grimm, 2008).

\section{Land in India}

Land has become an increasingly controversial issue, with deep cleavages between positions of multiple stakeholders: policy makers, farmers, activists and business houses. Most of the prominent cases are about conversion of agricultural land to either industrial or urban land. Other than the loss of fertile croplands, other issues of sustainability associated with land conversion such as loss of biodiversity, disruption of ecosystems, and so on, may or may not be at the forefront of these battles.

However, the sustainability angle cannot be ignored. The density of population on land has been steadily increasing, and hence there is already tremendous pressure on land and other natural resources (MSSRF, 2004). Preliminary IIHS analysis shows that the top 100 cities, home to 15 per cent of urban India occupies 8500 $\mathrm{km}$ or 0.265 per cent of total land. Further it can be estimated that the rest of urban India will occupy around 1 per cent of total land cover.

Seemingly, area under urbanisation is not of prime importance. However, there are other concerns. Nearly, 55 per cent of total land cover in India is arable (sown plus fallow land). This is one of the highest in the world, and there is not much scope to increase this land (CSE). The forest cover in India is also at 20 per cent. There is little scope, and it is unsustainable to increase agricultural land. The area under urbanisation has to be seen within this ecological constraint. But more importantly, and as mentioned above, there are huge indirect impacts of urbanisations, which are determined by the nature of land cover, land use and urban forms; thus how the land is used is of prime importance.

At the local scale, there is limited understanding of the nature of impact of urban growth on the quality of land, and functioning of the ecological services. There have been several studies on different forms of urban pollution, however similar studies on landforms and geomorphology are not common. One of these studies is Srivastava's study on Mumbai and its changing landform. After a quick overview of how the ecology of Mumbai has been altered over the past few centuries, the paper addresses the issue of increased demand for land, and resultant increased reclamation, and its resultant impact.

\section{Land Cover and Land Use}

Urban land cover and use changes are complex, and still not clearly understood. However, in recent times, remote sensing and other allied technologies have made detection of these changes easier and more accurate. Mapping of land use and land changes have provided tools to understand urban growth and dynamics. While urban form has been the subject of inquiry of scholars from many disciplines, availability of remote sensing data and GIS have provided an opportunity to apply various landscape metrics to an urban setting. Moreover, it is now possible to undertake spatio-temporal studies of a city's changing form, as seen later in the paper.

While there are quite a few studies that measure land use and land cover changes for cities globally, there are only a handful of these for Indian cities. Some of these are exercises to measure the accuracy of existing tools e.g., Wentz (2011) deployed expert system classification developed in Phoenix to understand urban expansion in Delhi, while Neighbergall et al. (2008) used remote sensing data to classify informal settlements in Delhi. In yet another study on Delhi, Kumar (2009) studies the land- cover change to understand 1) agriculture to urban land conversion and 2) natural to urban land conversion in this city.

Fazal's (2000) study is one of the rare studies that examines land cover changes in a non-metro India city. It uses remote sensing to study the loss of agricultural land for urban expansion in Saharanpur. The study points out that while there is a substantial loss of agricultural land in the city, not all of it is converted into urban areas, but pockets of land are lying vacant. The paper demonstrates that land use and land cover change are clearly linked to the operations of the land market.

In order to close some of these gaps, researchers at IIHS are examining land cover and land use change in around 400 cities, with the intention of gaining a better idea of the pattern of urban growth in India.

Glaring gaps on the Indian side notwithstanding, most international work too has focused on change in population, and change in extent of area. These tell little about pattern of urban change, and also do not give an idea of the drivers of these changes (Seto and Fragkias, 2005). It has also been argued that the theories that have explored the sprawl have mostly considered the social and economic aspects, while neglecting the ecological and environmental aspects (Yu and Ng, 2005). They also highlight the divide between temporal and spatial datasets, and limited attempts to bring two together, to understand specific processes driving urban change.

\section{Urban Morphology, Fragmentation}

\section{and Densities}

In addition to understanding the extent and causes of urban expansion, it is also equally important to understand the form of this expansion, as it affects resource use and consumption patterns.. While there is agreement that there is rapid urban expansion, there have been virtually no studies that have tried to understand the exact pace and nature of urban expansion: whether the cities are growing through infill, expansion or leapfrogging. There is also limited evidence on the degree or nature of fragmentation of Indian cities. There are limited numbers of studies on urban densities too; some of these are described below.

Dowall and Monkkenen (2007) examine urban densities in Chennai, while primarily focusing on links between densities and land values. The paper suggests that the city is growing both because of increasing density in inner city areas, as well as an expansion of city boundaries. It found that 
densities in Chennai vary drastically from as low as 13 persons per hectare to more than 1000 persons per hectare. Studying changes between 1971 and 2001, the study found that densities in the city grew faster than predicted, and also that the density gradient of the city had flattened out over the decades. Although it found a decrease in conversion to urban land. It also observed that the amount of land taken out of agriculture was seven times compared to land actually utilised for urban expansion. The authors point out that high densities in the central city are not on account of high rise buildings, but because of overcrowding.

The above study points out that nature of density is as important as the measure of density. The study by Patel (2011) is an attempt to set a framework on understanding densities, and its relation to other factors that contribute to desirable urban living. The paper studies the interrelationships of six parameters: built up area per capita, public ground per capita, plot factor, floor space index, gross densities and net densities. It aims to arrive at a range of desirable values with a combination of these parameters while designing and planning an area between 20 and 200 hectares of land. This is done by plotting characteristics of select localities in Mumbai and New York. While this paper misses most sustainability aspects, it is one of the first attempts to answer the question of optimal densities in Indian cities.

Globally, one of the most comprehensive studies carried out on urban densities, has been by Angel et al. (2005). In a World Bank study examining the dynamics of global urban expansion, their study has used population data and satellite images over two-time periods to measure the urban extent and expansion for a sample of 120 cities sampled with a population in excess of 100,000. The study also developed econometric models to explain the variation of urban extent and expansion.

Building on the data of 120 cities above, a series of working papers have been published by the Lincoln Land Institute. Angel et al. (2010 a and b) study different aspects of the urban sprawl, and focus on two aspects: densities and fragmentation. While stressing the need to separate the two aspects, they highlight how each of these is influenced by different drivers: densities are dependent on lifestyle preferences, cheap transport and cheap landprices, whereas fragmentation is largely the result of the operations of the land market. The study also highlights the difference in the nature of infills: cities with more car dependency are more easily filled in with local densities. Hence it is also important to separate the strategies for preventing infill from increasing densities.

In their essay on densities Angel et al. (2010 b), report the consistent decline in urban densities across the globe, in the period between 1990 and 2000. The paper selects several different parameters for measuring urban densities, which reflect average densities as well as density curves. It also highlight the high degree of fragmentation. Some of the factors that affect the densities of the city are: income levels of the city, natural geographical constraints, levels of inequality in the country, percentage of informal settlements, and availability of arable land and population of the city.

While densities have been on the decline, urban fragmentation is on the decline too. While this decline is welcome, it was found that cities still on an average contain or disturb an area of open space equal to that of their built up area. Like densities, they measure fragmentation through several metrics. While examining the causes of urban fragmentation, the study finds that the densities of the city do not affect the fragmentation levels, but level of car ownership, and availability of shallow aquifers did. It also found that stricter restrictions on conversion of agricultural to urban land reduced fragmentation. Also, informal settlements led to greater infill of urban areas, and thus decreased fragmentation. The authors also tried to understand the decline in fragmentation and some of the significant reasons discussed were decline in densities and increase in population of the city.

While the above represents some studies with widest geographical coverage, there are other international studies that examine fragmentation and densities. However, a limitation of most of these studies is that they examine these issues at city-wide level, and do not necessarily examine these at a smaller scale, understanding the differences in patterns within a city. While there have been such detailed studies done of individual North American and European cities, there are fewer studies in Asia. Some of the recent works have been located in China.

Seto and Fragkias (2005) examine four Chinese cities in the Pearl Delta Region, in which spatio-temporal analysis across three buffer zones was carried out over a decade. The paper also attempts to understand the underlying socio-economic processes (change of central planning to partially market-driven, land-use decisions taken at different levels of government, with only a partial dependence on infrastructure) that drive the physical changes. Yu and Ng undertake a spatio-temporal study in Guangzhou, and examine two urban rural transects. They find that while there is an obvious rural-urban-rural gradient, the region also demonstrates a multi-nucleated pattern, with differing rates of urban growth. They also examine the underlying causes, including natural barriers, real estate mechanisms and also FDI.

While the studies demonstrate an important breakthrough in the understanding of urban dynamics, there are various other aspects of land utilisation in urban areas. For example, both studies above conclude that urban areas have a tendency to expand, and then gradually fill in and become contiguous. However, there is still a need to understand what is happening within a particular land use: what is the nature of densities, what is the job- residential balance, what is the type of transportation system. One of the reasons, as Cadenasso (2007) points out is that most of land cover and land change methods are not adequate, as they do not capture urban heterogeneity well enough; these capture urban expansion, but not urban granularity at the block level. A combination of tools may be required to answer these questions. However, these papers begin to get to the heart of the question of drivers of urban change. This is explored in detail in the next section.

\section{Drivers of Urban Expansion and Form}

Given the rapid rate of expansion, it is equally important to understand the drivers of urban expansion. While the population of the city is one the reasons, there are other important causes at work. There are a couple of papers that have examined these for some of the metropolitan Indian cities. Kennedy (2007) is an attempt to understand peri- urban dynamics in Hyderabad from both macro and micro perspectives. The paper identifies several significant changes in Hyderabad: emergence of new business parks, 
construction of new high income residential colonies, and the attempt to create world-class infrastructure. At a macro level, the paper identifies both the need and the opportunity for Indian states, after economic reforms, to attract private capital, and foreign investments in particular. The TDP-led Andhra Pradesh government was arguably one of the first to move in this direction, and thus Hyderabad became the prime vehicle for economic growth. At a city level, the government chose to make it attractive by a slew of measures including relaxation of zoning and other byelaws on the provision of 'world class' services, land concessions on the provision of high-paying jobs, and creation of HITEC cities. The need for these exclusive enclaves meant that this development has taken away the central congested part of the city, and in the peripheries of the city.

The above paper highlights one of the most important changes in Indian cities: the influence of significant amount of private capital in Indian cities, and this is leading to fragmentation of cities. Also, as Kennedy (2005) points out in the case of Hyderabad, large tracts of peri-urban land are being converted into private enclaves, with special governance mechanisms. This is also true for Bangalore with special authorities to govern the Bangalore Mysore Infrastructure Corridor, and the Bangalore Airport (IIHS Kengeri Study). This spatial differentiation in an already fragmented urban institutions landscape is a cause for concern because any kind of urban ecological planning will certainly require an integrated landscape.

While the private enclaves in India are not driven primarily by ecological concerns, this is not the case globally. Hodson and Marvin (2010) illustrate that in many cities the primary response to the concern for urban ecological security has been the creation of private enclaves in the form of eco-cities, eco-towns, and floating cities. They point out that these endeavours largely depend on bypassing existing infrastructure, and creating exclusive infrastructures.

While some of the above studies on land do trace linkages between land and infrastructure development, these linkages are made more explicit in the following sections. The degree of path dependency between infrastructure and urban growth is not clear: in their study in China, Seto and Fragkias (2005) state that city expansion is not necessarily tied to public provisioning of infrastructure, while Angel et al. at a global scale find a close relationship between urban growth and infrastructure. Nevertheless, infrastructure often has considerable land requirements, and has a long life. It is therefore important to understand the relationship of some of the key infrastructures with land.

There are also severe gaps in the current policy framework to address the issue of land sustainability. The most common tool is Environmental Impact Assessment; this tool has several shortcomings which can be addressed here. However, the biggest drawback of this tool is possibly that it is meant for individual projects, it does not address the impact of multiple projects in one particular area.

Land is protected under the Wildlife Conservation Act, and Forest Protection Act, but there is no other device to look at other ecological impacts. One exception to this is the Coastal Regulation Zone Act, which seeks to protect coastal zones of India. It is hoped that this panel can recommend the next possible steps to influence the policy climate.

\section{Key Research Questions}

cities and what is the ecological significance of these patterns? What are the factors responsible for these patterns?

How can land be valued, other than monetarily, and integrated into policies? How have different countries dealt with this issue? What are the methods for evaluating the impact of sprawl on ecosystems?

What are the suitable metrics for studying urban densities? What are the ecological implications of specific urban densities in different contexts? From the perspective of urban sustainability, are there optimal densities for Indian cities? If so, what factors does it depend on?

\section{Urban Water infrastructure: Land and Environmental Implications}

Historically, settlements in India, were highly dependent on, and restrained by the local availability of water. Hence, across the country, depending on ecological conditions, one sees a host of different approaches ranging from direct utilisation of surface water from rivers and lakes to rainwater harvesting practices to more complex conjunctive water management as in the case of J odhpur, and underground canal systems as in the case of Burhanpur (Narain and Agarwal, 1990).

These water management systems were closely integrated with the planning of the city thereby reducing ecological impacts of both city building and water supply. In some senses, with modern technology, cities in India overcame water restraints, as it became possible to both dam water and transport it over great distances and also dig deeper to maximise ground water extraction. Modern water supply infrastructure in the larger Indian cities has mostly centered on large-scale surface impoundments and canals and pipelines for long distance water transfer (Mukherjee, 2010). However, over the past decades Indian cities have in most cases grown independently of the feasibility of providing water supply. While most Indian cities face water supply shortages, the highest infrastructure deficits are on the side of waste water. Waste- water and storm-water infrastructure has often not kept pace with rapid urban growth leading to environmental deterioration and increased incidence of urban floods.

This can be mostly attributed to paradigms of urban development where urban and infrastructure planning have been largely divorced from local specificities of hydrology.

In order to progress towards the ideal of urban sustainability it is important to understand the multiple linkages between hydrology, urban planning and water infrastructure. The following section first examines the relationship between water supply infrastructure and land, and then looks at the relationship between urban planning and water. It also examines the socio-ecological implications of water use in the city, and the policies which govern them.

\section{Urbanisation and Water}

At the national level, many of the rapidly growing urban centres happen to be in arid and semi-arid regions and rely on water transfers from further and further away in order to meet their requirements. For instance, there are proposals to develop new cities in some of the driest regions of the country as part of the Delhi Mumbai Industrial Corridor (delhimumbaiindustrialcorridor.com) 
Water being such a critical resource for cities, instead of locating new urban centres in arid and semi-arid regions and depending on long-distance water transfers (Mukherjee et al. 2010), they could be located in more ecologically appropriate zones where water demand would be lower and availability higher.

Although the National Water Policy (2002), recommends a close integration of water use and land use policies, and suggests that economic activities including agricultural, industrial and urban development should be regulated according to such a national water zoning, this is rarely the case when it comes to new urban development. Measures are required to ensure that comprehensive socio-ecological impact studies related to water sourcing are carried out to compare and evaluate options before locating new urban centres. Besides, policy measures are also required to ensure that appropriate infrastructure planning precedes the growth of new cities rather than following in their wake with much delay.

\section{Water Supply and Waste Water}

Urban areas draw upon a vast regional territory to provide water to the resident populations. A city like Mumbai draws water from upto $150 \mathrm{~km}$ away from the upper Vaitarna lake which is closer to Nashik than Mumbai (Gandy, 2008), while New Delhi gets water from the Tehri dam which is almost $300 \mathrm{~km}$ away. Using data from the survey of water utilities completed by the National Institute of Urban Affairs (NIUA) in 2002, Mukherjee et al. (2010) identify cities with larger populations to be relying more on surface water as opposed to ground water sources. The study also finds that larger cities that rely on surface water sources tend to supply higher volume of water per capita.

The above trend of constantly expanding water footprints, often, lead to conflicts in a densely and relatively uniformly populated country like India. The case of Chennai and the Telugu-Ganga project is an excellent example of urban water demand leading to conflict at the regional scale. Farmers along the upper riparian area of the Krishna river in Andhra Pradesh have strongly protested water transfer from the river to meet the water requirements of the city of Chennai (Nikku, 2004). Besides, larg-scale inter-basin water transfers of this nature also have the potential to negatively impact the riparian ecosystem if the quantity of water in rivers is not sufficient for normal ecosystem functioning (Bunn and Arthington, 2002).

Chennai also illustrates the impact that urban water demand can have on peri-urban areas. The purchase of groundwater by the city from farmers in the peri-urban area (Munian, 2010) has caused substantial changes in peri-urban land-use preferences (Ruet et al. 2007). In this case it could be argued that this is primarily a result of rational choice on the part of the farmers without much coercion from the city, since the farmers find it more lucrative to sell the water rather than sell the crops grown with the same water. Cities like Hyderabad (Celio and Giordano, 2007) and New Delhi (Swain, 1998; Delhi Gets Water Share, 2011) are also in perpetual negotiations with surrounding agricultural areas for their water supply.

While the above examples demonstrate the regional and peri-urban consequences of expanding water footprints, there can be negative consequences of a local scale within the city too. This is often due to over-extraction of groundwater resources in urban areas.
Using data from the NIUA survey, Patel and Krishnan (2009) demonstrate the extent of dependence of smaller cities on groundwater sources for their water supply. On average dependence on groundwater is only about 11 per cent for metropolitan cities while this increases to 49 per cent for Class II cities. Since the survey was only of municipal water supply, the actual level of dependence on groundwater is bound to be substantially higher due to the prevalence of private dug wells and bore-wells in urban areas. In many Indian cities like Bangalore, newer development on the urban fringe relies on groundwater since public infrastructure lags behind the initiative of private capital and housing demands. To ascertain the true extent of dependence on groundwater sources it is necessary to do studies which take into account private wells also.

The excess drawdown of aquifers can result in land subsidence and aquifer destruction as demonstrated by ample evidence available from cities like Mexico City, Beijing and the central valley in California (Caldecott, 2010). In coastal areas, intrusion of salt water is another major risk and the city of Chennai (Munian, 2010) and the Gujarat coast (Shah, 2008) are significantly affected by this. Attempts have been made to remedy this and in the case of Chennai, active recharge of aquifers has helped reduce salt water intrusion (Narain, 2005). However, rainwater recharge operations in Chennai have met with only partial success due to lack of supervision and care in the construction of recharge structures (Sreenivasan, 2008). Effective groundwater recharge efforts need to be guided by studies which identify suitability of different soil and hydrogeological conditions for recharge, since otherwise well-intentioned efforts can have unintended consequences of soil salinity, water logging and damage to buildings due to a rising water table.

Urban groundwater is therefore an area that requires urgent policy attention. It is a particularly complex policy domain since regulations regarding groundwater extraction are extremely difficult to enforce due to the near impossibility of monitoring an almost invisible resource which can be extracted by completely decentralised means. To compound matters, the existing water laws provide landowners with ownership of water beneath their land (Iyer, 2007). This legal framework clearly lacks any basis in ecological realities and needs to be urgently rethought.

Besides aquifer destruction, water pollution, both ground and surface, is one of the biggest consequences of urbanisation. Urban areas both affect, and are affected by water quality.

Domestic sewage is a major source of groundwater contamination both due to improper disposal of sewage and leakages in the sewer network. The groundwater in Bangalore is artificially recharged and the aquifer polluted by leaking sewer lines and disposal of sewage into the lakes of Bangalore. (Gronwall et al. 2010; Groundwater Report of Karnataka cited in Kozhisseri, 2005; Singh et al. 2010). Lack of adequate waste water treatment has led to the eutrophication of lakes in and around Delhi, Ahmedabad, Bangalore and Kolkata (Aggarwal and Butsch, 2011) due to discharge of partially treated or untreated sewage. Rivers like the Yamuna and Ganga have become little more than drains for industrial and urban effluents. Approximately 48 per cent (1393 MLD) of untreated sewage flows into the Yamuna every day (Misra, 2010) turning it into an enormous sewage drain which barely flows during the summer. Data for less celebrated rivers is harder to come by since there is no comprehensive and 
transparent system of monitoring and reporting on the status of surface water resources of India.

Pollution can also affect urban water supply since water quality can be severely compromised by inappropriate land uses in the catchment of reservoirs or upstream regions of rivers. Organochlorine and organophosphate pesticides have been reported in municipal drinking water supply from surface sources in J aipur (Bakore, 2004) and Hyderabad (Sinha et al. 2011) respectively. In both cases the source of contamination is stated to be agricultural land-uses in the catchment of drinking water supply reservoirs. Given the dependence of larger Indian cities on distant surface reservoirs (Mukherjee et al. 2010) studies are required to ascertain the contamination of these water sources due to conflicting land-uses and environmental degradation in the catchment area. Appropriate watershed management initiatives can not only mitigate pollution risk but as demonstrated by the case of New York, it can even reduce investment required for water supply infrastructure (Pires, 2004).

\section{Urban Planning and Design}

While any land-cover change related to urban development is bound to have some impact on ground and surface water systems, integration of an understanding of ecological factors into urban planning and design can help mitigate some of these effects. For instance, appropriate land-use planning measures can significantly assist in groundwater recharge, and storm water management. Waste water infrastructure is another sector which can be integrated with ecosystem functioning through appropriate urban planning and design measures. Much of conventional waste water treatment relies on energy intensive electromechanical systems which, in the Indian scenario, often fail to treat waste water due to lack of energy (Putrid Ribbon, 2009). In this context, there may be significant opportunities to bring in land-intensive soft infrastructure like wetland-based water treatment systems which require minimum energy inputs. There is a need for research which looks into the collateral benefits such systems provide like habitat and recreational value in order to undertake a balanced assessment of their viability.

The waste water based aquaculture system in peri-urban Calcutta is an example of an alternative waste water treatment strategy which while being land intensive, provides for both nutrient cycling in the urban ecosystem and economic opportunities to the local community (Mukherjee, 2003). Urban agriculture efforts also need to be studied in detail for their role in shortening cycles of urban metabolism and urban waste management while promoting economic productivity of marginal land. However, in both urban agriculture and aquaculture, rigorous studies are required to ensure public health and safety standards.

Sensitive urban planning can also contribute significantly towards storm-water management and mitigation of flooding risk. Many cities in India, including cities which face chronic annual water shortages are inundated during the monsoons. In most cases the major reason for such increase in flooding is due to ecologically inappropriate land-use strategies which lead to the obstruction of drainage channels, construction in flood plains and the paving over of marshlands which formerly provided valuable flood management services (Arunachalam, 2005).

As evident from reports in the popular press from time to time, proposals for 'waterfront' developments which capitalise on land availability in flood plains are abundant in the Indian context (Sreedharan, 2009; Expert Panel, 2011). The financial promise that such high-value real estate offers seems capable of negating concerns regarding ecosystem functioning and flood management. Since economic logic seems to take precedence over ecological understanding, studies regarding the economic value of ecosystem services provided by flood plains may be useful in guiding urban development.

Urban and architectural design can also significantly assist in storm-water management. Green-roofs, bioswales and water detention basins are simple and effective landscapebased strategies which help to mitigate peak run-off during storms. Storm water quality is also a serious concern since the run-off from urban areas often carries heavy metals and toxins originating from automobiles and industries, along with other organic pollutants, into surface and groundwater systems. Studies are required to evaluate and compare the efficacy of various land intensive and energy intensive methods of storm water filtration and treatment in order to protect both surface and groundwater sources.

\section{Water Infrastructure and Climate Adaptation}

Water is one of the critical limitations that Indian cities will face given climate change. Cities like Mumbai (Rode, 2008) and Chennai (Munian, 2010) demonstrate how urban water supplies in India closely track rainfall patterns in surface catchment areas. Water supply in both these cities depends on monsoon rainfall and in the case of Chennai, in the event of failure of the north-west monsoon, water has even been transported by rail from Vijayawada which is more than $400 \mathrm{~km}$ away (Nikku, 2004). Cities which depend on perennial rivers are also at risk due to climate variability and change since it can affect precipitation patterns in the upper reaches of the river basin and also cause accelerated retreat of glaciers.

Groundwater resources can contribute towards reducing climate vulnerability of urban water supply systems (SFPUC, 2011). Aquifers provide an opportunity for largescale water storage which may help buffer fluctuation in water availability and conjunctive management of ground and surface water management could be a significant part of climate adaptation strategies. Narain and Agarwal (1997) document the past prevalence of conjunctive water management in rural and urban India respectively. Given the dependence of Indian cities on groundwater resources (Patel and Krishnan, 2009), research on large-scale water recharge methods using both rainwater and treated waste water along with active management of aquifers, could contribute to climate adaptation of urban regions.

Increased climate variability can cause severe problems for storm water and waste water systems. While existing storm water systems run the risk of being overwhelmed by the increased likelihood of severe storms, waste water treatment facilities which often lie in low-lying areas run the risk of flooding and could be vulnerable to storm surges in coastal areas. In the case of cities which depend on rivers and seas to discharge treated (or often untreated) waste water, increased occurrence of floods and sea level rise can cause backflows and seriously disrupt the functioning of such infrastructure. (Major et al. 2011). 


\section{Key Research Questions}

How will climate change effect water dynamics of the city and what can a city do to prepare itself?

What are the key areas of intervention for improving urban water use efficiency, and reducing urban impact on local and regional hydrology? How can a city prioritise among these interventions based on local conditions?

Given the fragmentation of institutions in dealing with different aspects of water, what are the institutional interventions required to achieve integrated urban water management? What are the socio-ecological implications of long distance water transfers to urban centres and how can these be studied better?

At the watershed scale, how can land use be regulated to reduce pollution risk and improve water quality?

\section{Urban Energy and Land}

\section{Introduction}

Indian cities are dependent on a range of energy sources from hydropower and thermal to renewable sources and nuclear. According to the Ministry of Power (2011), coal and large hydropower still accounts for the total energy mix in the country to a large extent. As the country embarks on a more rapid growth trajectory one of the major challenges will be shifting this energy mix to a more sustainable one which has a high proportion of renewables in the long term, (which account for only 11 per cent currently). However, it has to be noted that large scale deployment of renewable energy (tidal, solar, biofuels) is highly land intensive (like conventional sources such as coal and thermal) and can potentially come in conflict with other socio-economic and ecological functions of land. Hence there are important land implications on the energy generation side. However, these have limited impact on urban areas, and are generally limited to areas near generation.

This paper focuses more on the demand side, and examines the linkages between cities and energy consumption. This section of the paper will first examine how urban spatial patterns and land use have a significant bearing on energy consumption and then conclude by outlining the linkage between urban energy generation infrastructure and environmental quality. Since cities use a bulk of the energy, we need to be aware of the indirect impact on land that urban energy choices can have

\section{Urban Energy Intensity and Demand-side Issues}

\section{Energy Intensity of Cities}

Energy intensity refers to the ratio of energy use and economic productivity. Energy intensity of Indian cities is extremely high when we compare it to similar-sized cities in developed countries. The energy intensity of the Indian economy is 3.7 times that of J apan and 1.5 times that of the USl. It has to be borne in mind that energy intensity is a function of many different parameters like low calorie fuel, inefficiency of buildings and equipment, low tariffs, leakages in distribution, weather and the nature of economy (Kalra and Shekhar, 2006). For instance cities that are located far away from sources of water may have a higher energy intensity since the energy required to provide daily water supply itself can be very substantial. In spite of its dependence on a host of factors, it is a useful metric to remind ourselves that there is substantial scope for improvement in the energy efficiency of our cities.

\section{Transportation, Land Use and Energy Consumption}

Transportation is one of the biggest consumers of energy in cities and urban land use, densities, and transportation infrastructure choices are very closely interlinked. Globally there are numerous studies which demonstrate this relationship and highlight the significance of high- density public transit based development in reducing overall urban energy consumption.

Newman and Kenworthy (1989) state that gasoline consumption in 10 large US cities varies by up to 40 per cent primarily due to differences in land use and transportation factors rather than price or income variations. Studies have shown that more intensive the land use, shorter the distances of travel, greater the viability of transit (more people per stop and hence better service), greater the amount of walking and biking, higher the occupancy of vehicles, and overall, leading to a reduced need for a car. These patterns suggest that the urban structure within a city is fundamental to its energy consumption (Newman and Kenworthy, 1989).

The two main goals of planning for high density in the context of transport energy consumption involve reducing trip length and total mobility by concentrating residential, employment and services areas and changing the modal split to reduce the share of private car use in relation to public transportation, walking, and cycling (Cervero, 1988 and Barrett, 1996; as cited in Mindali et al. 2004). Based on simulation studies of Bangalore, Lefevre (2009) predicts that in a business-as-usual scenario, transportation energy consumption and emissions would increase by 70 per cent with respect to 2003 levels.

Building Energy

\section{Consumption and Embodied}

\section{Energy}

Although compact and dense cities clearly have the potential to reduce energy consumption for transportation they may promote an increase in the embodied energy and operational energy consumption of buildings in cities. Parikh and Shukla (1995) note that increased urban density and high land value in close proximity to agglomeration of economic activities (such as a central business district) makes it economically necessary to have high-rise buildings which involve the use of energy intensive materials and construction methods.

\section{Urban Heat Island Effect}

\section{and Energy}

\section{Consumption}

Madlener et al. (2011) identify the urban heat island (UHI) effect as a distinctive feature of compact and dense cities. Sealed surfaces such as roads, buildings, and other constructed surface areas absorb and retain solar radiations. The displacement of trees reduces natural cooling effects of shading and evapotranspiration. As a consequence, the UHI effect increases the city air temperature by $1-3^{\circ} \mathrm{C}$ relative to the surrounding area and this can then lead to increased energy consumption for maintaining thermal comfort in buildings. Urban land use would therefore have to balance density and compactness with reduction in the urban heat island by incorporating green spaces and shady trees (Rosenfeld et al. 1995). 
There is evidence from Indian cities also regarding the importance of urban green areas and meso-climate sensitive planning in reducing urban energy consumption. According to Deosthali (2000), in the case of Pune, the core of the city is a heat and moisture island at night influenced to a great extent by surrounding topography and prevailing winds. Based on the study, Deosthali suggests that the heat island could be mitigated if urban planners promote good circulation of the westerly winds through the city. This clearly shows that land-use planning which takes into account local environmental conditions can substantially influence urban energy intensity.

\section{Cities and Energy Production}

Although urban areas are thought of more as consumers of energy rather than sources of energy generation, many cities do have large-scale energy generating infrastructure like thermal power plants. With the increasing emphasis on renewable it is also quite possible that cities of the future may generate a substantial portion of their energy requirements. There are hardly any studies at present about urban spatial patterns which may be necessary to ensure access to renewable sources like sun and wind.

Another urban energy source that is often ignored is biomass. While rural India is widely known to be dependent on various forms of biomass for fuel, according to the National Sample Survey, 2001, 20 per cent of urban India also depend on fuel wood to meet its energy needs. This figure was estimated to be 30 per cent in 1993 and the decline is largely due to a gradual shift to liquefied petroleum gas (Pandey, 2002). Despite the decline in the proportion of households using fuel wood, the total demand for fuel wood has been increasing due to the increase in number of households. Dependence on fuel wood has the potential to cause local degradation of forests (De Fries and Pandey,

2009), but it is unclear whether this has any significant impact on green areas in and around cities.

The siting of large energy generation infrastructure like thermal power plants in cities can have substantial impact on surrounding land use and ecosystem. According to Gurjar et al. (2004), the thermal power plants of Delhi were responsible for about 68 per cent of SO2 and 80 per cent of TSP (Total Suspended Particles) between 19902000 .

In the case of Delhi, thermal power plants also effectively convert a large extent of the Yamuna waterfront into an industrial zone which essentially limits access to a large portion of the riverfront.

Pollution issues associated with such energy generation infrastructure also have the potential to influence land values with often the poor and the vulnerable bearing the brunt of the impact. Studies resolving these aspects of energy generation projects are hard to come by in India.

Private energy generation using diesel generator sets is also emerging as a major source of pollution in urban areas in India. This is primarily a result of commercial establishments resorting to diesel generator sets as a means of coping with unreliable power supply (Kalra and Shekhar, 2006).

\section{Key Research Questions}

What are the different pathways through which land use and densities affect urban energy consumption? What are the ecological implications of such relationships between land use/ densities and energy consumption? Which are the key pathways that need to be prioritised?
How can we study the relationship between densities, and the trade-off between energy requirements of transportation and building construction? In this context, are there optimal densities for Indian cities?

What are the key areas of intervention for improving energy efficiency, and reducing ecological impacts? How can a city prioritise among these interventions based on local conditions?

How does energy generation infrastructure in urban areas impact urban ecosystems?

\section{Transport of Cities}

The clearest linkage between land and mobility is seen if one examines the development of urban form and morphology historically, and how it has changed alongside the changing nature of transportation. In one of the earlier papers examining this connection,

Newman and Kenworthy (1996) trace three major phases in this relationship between land and transport:

- Medieval cities where walking was the major mode of cities;

- cities serviced by suburban rail and tram; and

- Cities where personal car was the dominant mode of transport.

Drawing mostly on examples of European and North American cities, they illustrate how the changes in the technology of transportation changed the compact form of cities to sprawling cities, sometimes with a diameter as large as $50 \mathrm{~km}$, from high density cities to low densities, from mixed use to single use. They argue that the spread of the automobile broke down the land-use- transport connection as it gave the freedom in 'time-space' to go in any direction, and for long distances. The transportation planners thought it was a matter of providing infrastructure, wherever it was needed. The paper marks a point which led to 'demise' of such thinking, and points out the social and environmental costs of automobiledependent cities.

More than a decade since their paper, problems of automobile-dependent transportation is well recognised by planners, policy makers and international agencies. There have been several studies that have documented the harmful consequences of automobile dependence. Moreover, given the realities of climate change, transportation, especially urban transport, has been an area of focus, as it accounts for substantial consumption of fossil fuels, as also for GHG emissions. Urban transportation then has moved away, from being merely a local concern to one with global implications. There has been a major push for public transportation, and nonmotorised modes from various quarters.

Before delving in the transport-land use connection both in India and internationally, the next section describes the current state of urban transportation in India.

\section{Transportation in Indian Cities}

India has seen a tremendous growth in ownership of motorised vehicles, both cars and two-wheelers, but the growth of two-wheelers has far outstripped that of motor cars (Iyer and Badami, 2007, Pucher et al. 2005). This increase in ownership is clearly reflected in the changing composition of the modal split of cities, e.g., Delhi has seen an increase in numbers of trips by two-wheelers. (Tiwari, 
2002). While this increase in vehicle ownership has severe environmental and social impacts, the rise in the increase of vehicle ownership is explicitly listed as one of the indicators of economic growth by the Government of India. (Badami, 2009). This is one example of contradictions at a macro policy level.

One of the reasons for the increased ownership of motorised vehicles in urban areas is the serious public transportation crisis in Indian cities. Only some cities in India have any form of public transportation; most other cities depend on various modes of personal transport or para-transit. Even in cities where public transport is available, it is grossly inadequate, of poor quality, and unreliable (Pucher et al. 2005). Mumbai, with its extensive network of suburban trains remains a notable exception. In many cities, this has shifted a lot of people from buses to two-wheelers, as the two-wheelers provide cheaper, reliable and the more flexible option (Badami and Iyer, 2007).

On account of poor public transport and increased motor vehicle ownership, the transportation issue that is the most visible and has managed to get most attention in policy circles is that of congestion. While the problem of congestion is increasing, the rate of vehicle ownership in India is a fraction of the vehicle ownership in OECD/ USA, and future trends show further increase in ownership. The dominant policy response to congestion has been to improve road infrastructure and improve movement of motor cars. Measures have comprised road widening, construction of flyovers, limited access expressways, synchronised signals, and area traffic control systems (Tiwari, 2002). These measures cost a lot of money. While these efforts have been implemented primarily to relieve congestion, it is not clear how much they will help in the long run. Various authors have demonstrated, through comparison with other countries that it is not a viable long-term solution (Badami, 2009; Tiwari, 2002). The increase in speed and decreased congestion is offset by diverting traffic from other routes, diversion from public transport, or increase in newer trips. Most of these above efforts still belong to the paradigm that measures mobility instead of accessibility (Litman, 2005).

Even as the convenience of car users remains the predominant concern, there still remain considerable section of population which cannot even afford public transport fares (Tiwari, 2002). In most cities, there is a captive population for walking and cycling, aided by traditional mixed use cities. Yet, the issue that gets least attention is lack of accessibility, especially for the pedestrians and cyclists. The environment for pedestrians is harsh: most cities have inadequate or no footpaths; where they exist, they are badly maintained and usually have several obstructions. In addition, there is an increasing tendency to put hard medians on roads, decreasing the number of places where pedestrians can cross. Budgets for provision of facilities for pedestrians and cyclists are minimal. In the case of pedestrians, the predominant trend has been to provide elevated skywalks (Mumbai), or creation of subways (New Delhi). Unsafe, inadequate pedestrian facilities lead to the increased use of motor vehicles, even for short distances (Badami, 2009). Ironically, poor families, whose primary modes of travel are cycling and walking, have been displaced to the periphery, not only because they have been priced out of the housing market, but also because of evictions. They have forced to use public transport or para-transit, which they can barely afford.

The inequity present in the transportation system is also apparent if one considers the two major public health challenges arising from transportation in India: traffic accidents, and increasing air pollution (Tiwari, 2003; Badami, 2009). Since air pollution affects everyone in the city, this issue has gained considerable prominence, and efforts have been ongoing to address it (Tiwari, 2003). The air pollution levels in Indian cities have been increasingly steadily, and exceed WHO standards. Vehicular emissions are a major contributor to such pollution. To curb vehicle emissions, a wide range of measures, including increasingly stringent emission and fuel quality standards, inspection and maintenance, the phasing out of old commercial vehicles, and the conversion of auto-rickshaws, taxis and buses to compressed natural gas, have been implemented since the early 1990s (Badami, 2009).

Compared to the issue of pollution, traffic accidents has hardly received any attention. One plausible reason is that traffic accidents are considerably skewed, affecting mostly pedestrians, cyclists, and two-wheelers. The elite and higher middle class, who are mostly car users, are not affected substantially by this issue. Also, whatever little attention that this issue gets is focused on fatalities, while the number of people suffering minor and major injuries is substantially higher. Traffic accidents have a serious socio-economic impact, especially if the accident results in the death or physical disability of the primary bread earner (Tiwari, 2002). Ironically, as pedestrians and cyclists, the people adversely affected by accidents also tend to be the ones who are least responsible for traffic accidents.

Besides the local environmental impact of air and noise pollution, the transportation section has serious global environmental consequences as it is responsible for 50 per cent of the petroleum consumption in India. This linkage between transportation and energy has been explained in the energy section.

In the context of the above challenges, it has been alleged by a number of authors (Badami, 2009; Tiwari, 2002 and 2003; Mohan, 2008) that the current policy and planning atmosphere still favours personal use of cars, even though the proportion of trips made by cars is a fraction even in the major metros. While the national transportation policy talks about encouraging non-motorised vehicles and pedestrians, there is little evidence for this on the ground. Most projects still are focused on expanding and widening the road network.

While there is some glimmer of hope, as some cities are making plans for the BRTS system under J NNURM, and a total of 15,000 buses have been ordered under J NNURM, this is far too little to check the growth of private vehicles (KCS,

2011). Moreover, even under J NNURM, more than 50 per cent of the approximately 8,000 crores committed to transportation projects are ear-marked for roads and flyovers (MoUD data, IIHS analysis). Under UIDSSMT, all the projects are road expansion or flyover projects. In addition, the metropolitan cities, aspire for rail-based systems, which are very expensive, even while it is unclear about the added advantage of these over bus-based systems (Mohan, 2008). 


\section{Transportation and Land Use}

Broadly speaking, most authors writing on urban transportation in India have commented on the natural advantage of Indian cities for non-motorised vehicles. Till now, most Indian cities have tended to be dense and mixed use, making it incompatible with road widening, but ensuring requisite densities for public transport. Also, a substantial proportion of low-income families ensure a captive population for walking and cycling. However, Indian cities instead of capitalising on this advantage are opting for low-density development. Now, ironically, poor people are being evicted from the central city to the periphery for road infrastructure projects, or are completely priced out of the land markets (Badami, 2009).

Surprisingly, other than general agreement among authors about issues mentioned above, there are few case studies that examine the urban form-transport connection in detail. Tiwari's (2003) paper examines the case of Delhi and makes a case about how the distribution of land uses serves a certain kind of transportation system, ie., how mixed, dense land use has favoured walking and cycling. She looks at how recent changes in land market and regulation have changed the current system: with the poor, and low middle classes being moved to the periphery.

In another comparative study, between Bangalore and Silicon Valley (Reillya et al. 2009), the authors set out to examine how accessibility to economic and social activities determine the urban form. They observe that historically Bangalore has had a dense mixed use urban core, easy access to jobs, mostly in the informal economy, and hence a large percentage of walking and public transportation trips. However, the landscape of Bangalore has been changing since the economic reforms in 1991.

The growth of the city, while fuelled by substantial private investment, has been strongly directed through public planning agencies, and has become the location of IT and other industries in the suburbs, particularly around Whitefield. This has certainly led to an increase in use of motorised vehicles. Even then, the study found a high percentage of walking and public transport trips, and found existing clusters of urbanisation (whether the central business district or major centres of development in the periphery) as a much better indicator of forecasting urban growth, rather than major roads.

Other than these rare studies, there is little understanding of the nature of connections between urban form, changes in mobility behavior, and public transport. As stated in the earlier section on land, there is little understanding of changing patterns of urban form itself in India. There has been a tendency in metropolitan cities to locate employment opportunities away from the city centre, e.g., Cyberabad in Hyderabad, and Gurgaon in NCR. This trend obviously has implications for residential preferences, and housing markets. But the effect of changing job and residential landscapes on transportation patterns (other than increase in number of vehicles) is not clearly understood. There are also no studies on non-work trips. While there are some studies carried out for metropolitan cities, there is almost no understanding of small and medium towns.

However, globally, as the need for public transportation has been more keenly realised, there have been attempts to understand the relation between mobility behavior and urban form in contemporary urban areas. Much of the work has been done on understanding the relation between automobile use, and urban form; studies that examine relation of form to other modes of travel are rare (Vance, 2007).

In one of the earliest international comparative studies that looked at patterns, and causes of automobile dependency, Kenworthy and Laube found a strong connection between automobile dependence, and land use pattern. The study compares 46 cities in North America, Europe, Australia, and Asia. Of all the factors considered for increase in automobile dependency, co-relation with urban form, especially density, was the highest, and authors have recommended this as the single most important point to reduce automobile dependence. The paper also mentions that most Asian cities already have sufficiently high densities, and the challenge there would be to ensure that transportation modes remain oriented towards public transport, and non-motorised modes of transport. There was little co-relation found between wealth of the city and use of public transit; also increase in car use did not necessarily increase the economic performance of the city. It was found that the cost of buying and using a car was inversely related to automobile dependency. Also, public transport usage was higher where there was rail-based system, and nonmotorised modes are significant in both economic and environmental terms. One of the major conclusions of the study was that the increasing use of the motor car is not inevitable, but is strongly shaped by planning and public policy. In addition to the recommendations of reshaping urban land use policy and investment in non-auto infrastructure, it also stresses the need to align the economic development policy with planning needs by internalising the true cost of car ownership and car use.

While later studies have confirmed the co-relation between urban form, supply of public transport and mobility behaviour, there remains a debate over the causality or atleast the degree of causality (Vance 2007). Most of these studies have been carried out in different cities in the US, as a reaction to the New Urbanism phenomenon. Since the 1990s, New Urbanism, or neo-traditional villages or neighbourhoods, which are essentially high density, mixed use neighbourhoods oriented walking and cycling, has been increasingly propagated in the US. There have been claims that these neighbourhoods influence mobility behaviour, and reduce automobile trips. In order to find evidence for these claims and to disentangle urban form, provision of public transport and mobility behaviour, various research studies have been carried out in various American cities.

These studies have been mostly quantitative in nature, and most have cited the need to be complemented by more qualitative studies (Bento et al. 2005, Khattak and Rodriguez 2005, Krizek 2003, Cervero and Krockman 1997) They have been complicated by several factors: some of them being endogeneity between mobility

behaviour of those in transit dependent neighbourhoods; there is concern that people who dislike driving may selfselect themselves into areas with public transport; and also endogeneity of urban form; and supply of public transit. There is also concern that these studies do not reflect socio- economic profiles of families, and variations caused by differences in income. Some debate has been over proxies for urban form: distance from CBD, provision of pathways, densities, mixed use, and supply of public transit. Studies like the ones mentioned above are limited to European cities. 
In addition to large gaps in the influence of urban form on land and mobility patterns, documentation of the harmful environmental impact of transportation is nearly restricted to emissions and air pollution. J ust as traffic accidents are almost forgotten in health literature, there is little mention of disruption of land fragmentation or loss of productive land. There is general agreement but little understanding of how an increase in paved areas is a major cause of local inundation or how the use of bitumen or concrete for roads might be causing ground water pollution. Road widening projects have led to, and continue to lead to, cutting of trees, especially in Delhi and Bangalore. There have been other deleterious effects of automobile-oriented transport, e.g., plans of building expressways on the beaches of Chennai.

\section{Key Research Questions}

What is the relationship between urban form (land cover, land use, densities) and travel behaviour and transportation systems in Indian cities? How can we examine these relationships better, especially in small and medium towns?

How is transportation demand in the city connected to livelihoods and the economy of the city? How does the nature of the urban economy contribute to sustainable/ unsustainable patterns of transportation?

What are the effects (first and second order) of current transportation systems on ecosystems?

How can the transport-land connection be emphasised and integrated into the contemporary policy discourse?

\section{The Context for this Background Note}

This background note is a precursor to a possible research programme on the sustainability of infrastructure and land. This was largely an exercise to examine the landscape of existing (published) work and identify significant gaps and a filtering of those gaps to identify the most important ones which have to be addressed from policy, action and/ or academic perspecives. We hope that the workshop will initiate that process of prioritisation.

A research project addressing the questions raised here on linkages between spatial patterns and resource use will be part of the larger IIHS programme on urban sustainability. One of the key objectives of the programme overall is to develop practical knowledge that can feed into existing practices and policy. Given the fact that most infrastructure development in cities is influenced by the national government through centrally sponsored schemes, and much of it through programmes like JNNURM, we are seeking to develop insights that can inform the programme for the second phase of J NNURM. We are also targeting urban land and planning policies, especially in the context of ongoing reforms. We hope the panel discussion will also help us identify other windows of opportunity in the next few years.

Apart from this, as next steps, we propose to undertake a review of existing data, institutional structures and policy guidelines which are relevant to the infrastructure sectors under study. The purpose of this extensive documentation and review is to have a broad overview that will enable us to focus on key/ strategic issues.

The analysis of land, infrastructure, and sustainability appears to be severely constrained by data limitations. While this paper has not examined separately the existing data, this would be one of the next steps that need to be undertaken. There is household data available for water and energy both from CENSUS and NSSO; there is also data available for major infrastructure at the city level, though not consolidated. While some issues of sustainability are addressed indirectly in these parameters more may be required. Also, while numerical data may be available, spatial datasets are available only with a few cities. Hence, one would identify these gaps, and look at opportunities to close these gaps. The parameters required at the city level could be piloted for specific cities through the IIHS Urban Indicators Project. It is particularly important as there is a huge degree of resource use that is not monitored, e.g., extraction of ground water, or the use of diesel generators.

There is also need to carry out a review of existing policies, and regulations on concerned issues. While there are relevant national policies on water, urban sanitation, energy and urban transport, these are state subjects, and hence one would need to examine these policies at the state level. It may be possible to pick up policies and regulations of a couple of states. It would also be required to review planning norms for states. There is also work to be done around the mapping of institutions which are responsible for different institutions. In the absence of adequate monitoring systems for sustainability, civil society groups have often protested, and filed public interest litigation, thus case law could serve as a rich source of information.

\section{References}

Aggarwal, S., \& Butsch, C. (2011). Environmental and Ecological Threats in Indian Mega-Cities. J ohn Wiley \& Sons, Ltd.

Angel, S., Parent, J ., \& Civco, D. L. (2010 a). The Fragmentation of Urban Footprints: Global Evidence of Sprawl, 1990-2000. Lincoln Institute of Land Policy.

Angel, S., Parent, J ., Civco, D. L., \&Blei, A. M. (2010 b). The Persistent Decline in Urban Densities: Global and Historical Evidence of 'Sprawl'. Lincoln Institute of Land Policy.

Angel, S., Sheppard, S. C., \& Civco, D. L. (2005). The Dynamics of Global Urban Expansion. Transport and Urban Development Department, The World Bank.

Arunachalam, B. (2005). Drainage Problems of Brihan Mumbai. Economic and Political Weekly, 40 (36), pp. 3909-3911.

Badami, M. G. (2009). Urban Transport Policy as if People and the Environment Mattered: Pedestrian Accessibility the First Step. Economic and Political Weekly, 44(33), 43-51.

Bakore, N., J ohn, P. J ., \& Bhatnagar, P. (2004).

Organochlorine Pesticide Residues in Wheat and Drinking Water Samples from J aipur, Rajasthan, India.

Environmental monitoring and assessment, 98 (1), 381-389.

Barrett, G. (1996). The Transport Dimension. In M. J enks, E. Burton, \& K. Williams (Eds.). London and New York: E\&FN Spon Publishers.

Bento, A. M., Cropper, M. L., Mobarak, A. M., \&Vinha, K. (2005). The effects of urban spatial structure on travel demand in the United States. The Review of Economics and Staticestics, 87(3), 466-478.

Bunn, S. E., \&Arthington, A. H. (2002). Basic Principles and Ecological Consequences of Altered Flow Regimes for Aquatic Biodiversity. Environmental management, 30 (4), 492-507. 
Cadenasso, M. L., Pickett, S. T., \& Schwarz, K. (2007).

Spatial heterogeneity in urban ecosystems:

reconceptualising land cover and a framework for classification. Front Ecol Environ, 5(2), 80-88.

Caldecott, J . (2010). Water: The causes, costs and future of a global crisis. Virgin Books.

Celio, M., \& Giordano, M. (2007). Agricultureâ€ "urban water transfers: a case study of Hyderabad, South-India. Paddy and Water Environment, 5 (4), 229-237.

Cervero, R. (1988). Land-use mixing and suburban mobility. Transportation Quarterly, 42 (3), 429-446.

Cervero, R., \& Kockelman, K. (1997). Travel demand and the 3Ds: Density, diversity and design. Transpn Res.-D, 2(3), 199-219.

Deosthali, V. (2000). Impact of rapid urban growth on heat and moisture islands in Pune City, India. Atmospheric Environment, 34 (17), 2745-2754.

Dowall, D. E., \& Monkkonen, P. (2007). Dense and Expanding: Urban Development and Land Markets in Chennai, India. Institute of Urban and Regional Development, University of California.

Expert panel in the offing to monitor riverfront realty growth. (2011, My 13). Expert panel in the offing to monitor riverfront realty growth.

Fazal, S. (2000). Urban expansion and loss of agricultural land - a GIS based study of Saharanpur City, India. Environment and Urbanisation, 12(2), 133-149.

Foley, J . A., DeFries, R., Asner, G. P., Barford, C., Bonan, G., Carpenter, S. R., et al. (2005). Global Consequences of Land Use. Science, 309, 570-574.

Frid, C., Andonegi, E., Depestele, J ., J udd, A., Rihan, D., Rogers, S. I., et al. The environmental interactions of tidal and wave energy generation devices. Environmental Impact Assessment Review (0).

Newman, \& Kenworthy, J . R. (1996). The land usetransport connection: An overview. Land Use Policy, 13(1), 1-22.

Newman, \& Kenworthy, J . R. (1989). Gasoline Consumption and Cities. J ournal of the American Planning Association, 55 (1), 24-37.

Gandy, M. (2008). Landscapes of disaster: water, modernity, and urbanfragmentation in Mumbai. Environment and Planning, 40, 108-130.

Grimm, N. B., Faeth, S. H., Golubiewski, N. E., Redman, C. L., Wu, J., Bai, X., et al. (2008). Global Change and the Ecology of Cities. Science, 319, 756-760.

Grimm, N. B., Faeth, S. H., Golubiewski, N. E., Redman, C. L., Wu, J., Bai, X., et al. (2008). Supporting Online Material for Global Change and the Ecology of Cities. Science, 319, 756-766.

Gronwall, J. T., Mulenga, M., \& McGranahan, G. (2010). Groundwater, self-supply and poor urban dwellers A review with case studies of Bangalore and Lusaka. Human Settlements Working Paper Series, International Institute for Environment and Development.

Gurjar, B. R., van, J . A., Lelieveld, J ., \&Mohan, M. (2004). Emission estimates and trends (1990â€"'2000) for megacity Delhi and implications. Atmospheric Environment, 38 (33), 5663-5681.

GWEC. (2011). Indian Wind Energy Outlook 2011. Global

\section{Wind Energy Council.}

Hodson, M., \& Marvin, S. (2010). Urbanism in the anthropocene: Ecological urbanism or premium ecological enclaves? City, 14(3), 298-313.

Iyer, N. V., \& Badami, M. G. (2007). Two-wheeled motor vehicle technology in India: Evolution, prospects and issues. Energy Policy, 35, 4319- 4331

Iyer, R. (2007). Towards Water Wisdom: Limits, J ustice, Harmony. New Delhi: Sage Publishers.

Kalra, P., \& Shekhar, R. (2006). Urban Energy Management. In A. Rastogi (Ed.). Oxford University Press.

Kennedy, L. (2007). Regional industrial policies driving peri-urban dynamics in Hyderabad, India. Cities, 24(2), 95-109.

Kenworthy, J . R., \&Laube, F. B. (1999). Patterns of automobile dependence in cities: an international overview of key physical and economic dimensions with some implications for urban policy. Transportation Research Part A, 33, 691-723.

Khattak, A. J ., \& Rodriguez, D. (2005). Travel behavior in neo-traditional neighborhood developments: A case study in USA. Transportation Research Part A, 39, 481-500.

Kozhisseri, D. (2005, September 30). Groundwater dip: quantum, quality. Groundwater dip: quantum, quality.

Krizek, K. J . (2003). Neighborhood services, trip purpose, and tour-based travel. Transportation, 30, 387-410.

Kumar, P. (2009). Assessment of Economic Drivers of Land Use Change in Urban Ecosystems of Delhi, India. AMBIO: A J ournal of the Human Environment, 38(1), 35-39.

Lambin, E. F., Geist, H. J ., \& Lepers, E. (2003). Dynamics of Land-Use and Land-Cover Change in Tropical Regions. Annu. Rev. Environ. Resour., 28, 205-241.

Lambin, E. F., Turner, B., Geist, H. J ., Agbola, S. B., Angelsen, A., Bruce, J . W., et al. (2001). The causes of land-use and land-cover change: moving beyond the myths. Global Environmental Change, 11, 261-269.

Litman, T. A. (2003). Measuring Transportation: Traffic, Mobility and Accessibility. ITE J ournal, 73(10), 28-32.

Madlener, R., \& Sunak, Y. (2011). Impacts of urbanisation on urban structures and energy demand: What can we learn for urban energy planning and urbanisation management? Sustainable Cities and Society, 1(1), 45-53.

Mindali, O., Raveh, A., \& Salomon, I. (2004). Urban density and energy consumption: a new look at old statistics. Transportation Research Part A: Policy and Practice, 38 (2), 143-162.

Ministry of Power. (2011). Retrieved October / 28, 2011, from http:/ / www.powermin.nic.in/J SP_SERVLETS/ internal.jsp

Misra, A. K. (2010). A river about to die: Yamuna. J ournal of Water Resource and Protection, 2, 489-500.

Mohan, D. (2001). Planning for Public Transport: Integrating Safety, Environment and Economic Issues. Workshop on Transportation, Land Use and the Environment, Pune.

Mohan, D., \& Tiwari, G. (1999). Sustainable Transport Systems: Linkages between Environmental Issues, Public Transport, Non-Motorised Transport and Safety. 
Economic and Political Weekly, 1589-1596.

MoUD. (2008). Study of Traffic and Transportation Policies and Strategies in Urban Areas in India. Ministry of Urban Development.

MSSRF, \&WFP. (2004). Atlas of the Sustainability of Food Security in India. M.S. Swaminathan Research Foundation.

Mukherjee, I., \& Gopal, M. (1996). Chromatographic techniques in the analysis of organochlorine pesticide residues. J ournal of Chromatography A, 754 (1-2), 33-42.

Mukherjee, M. (2003). Waste-Fed Fisheries in Peri-urban Kolkata. Urban Agriculture Magazine.

Mukherjee, S., Shah, Z., \& Kumar, M. D. (2010). Sustaining Urban Water Supplies in India:Increasing Role of Large Reservoirs. Water Resources Management, 24, 2035-2055.

Munian, A. (2010). Dynamics of Residential Water Demand and Supply in India: A case study of Chennai City. New Delhi: Gyan Publishing House.

Narain, B. L. (2005). Water scarcity in Chennai.

Narain, S., \&Agarwal, A. (1997). Dying Wisdom: The rise, fall and potential of India's traditional water harvesting systems. Delhi: Center for Science and Environment.

Nikku, B. R. (2004). Water rights, conflicts, and collective action: The case of Telugu-Ganga Project, India.

Pandey, D. (2002). Fuelwood studies in India: myth and reality. Bogor, Indonesia: CIFOR.

Patel, A., \& Krishnan, S. (2008). Groundwater situation in urban India: Overview, opportunities and challenges. In U. A. Amarasinghe, T. Shah, \& R. P. S. (Eds.). Colombo: International Water Management Institute.

Patel, S. B. (2011). Analyzing urban layouts - can high density be achieved with good living conditions? Environment and Urbanisation, 23(2), 583-595.

Pires, M. (2004). Watershed protection for a world city: the case of New York. Land Use Policy, 21 (2), 161-175.

Pucher, J ., Korattyswaropam, N., Mittal, N., \&Ittyerah, N. (2005). Urban transport crisis in India. Transport Policy, 12, 185-198.

Reillya, M. K., O’Mara, M. P., \& Seto, K. C. (2009). From Bangalore to the Bay Area: Comparing transportation and activity accessibility as drivers of urban growth. Landscape and Urban Planning, 92, 24-33.

Rode, S. (2008). Public private partnership in drinking water supply of Greater Mumbai. Urban Studies.

Rosenfeld, A. H., Akbari, H., Bretz, S., Fishman, B. L., Kurn, D. M., Sailor, D., et al. (1995). Mitigation of urban heat islands: materials, utility programmes, updates. Energy and Buildings, 22 (3), 255-265.

Ruet, J ., Gambiez, M., \& Lacour, E. (2007). Private appropriation of resource: Impact of peri-urban farmers selling water to Chennai Metropolitan Water Board. Cities, 24 (2), 110-121.

Seto, K. C., \&Fragkias, M. (2005). Quantifying spatiotemporal patterns of urban land-use change in four cities of China with time series landscape metrics. Landscape Ecology, 20, 871-888.

Seto, K. C., Fragkias, M., Guneralp, B., \& Reilly, M. K. (2011). A Meta-Analysis of Global Urban Land Expansion.
PLoS ONE, 6(8), 1-9.

SFPUC. (2011). San Francisco groundwater supply project: Creating local and reliable water sources. San Francisco groundwater supply project: Creating local and reliable water sources, 2011 (October/ 17).

Shah, T. (2008). Taming the Anarchy: Groundwater governance in south-asia. New Delhi: Routledge.

Singh, J . M., Davis, D., Somashekhar, R. K., Prakash, K. L., \& Shivanna, K. (2010). Environmental isotopes investigation in groundwater of Challaghatta valley, Bangalore: A case study. African J ournal of Environmental Science and Technology, 4 (4), 226-233.

Sinha, S. N., Vasudev, K., Vardhana, M. V., \& Odetokun, M. (2011). Quantification of organophosphate insecticides in drinking water in urban areas using lyophilisation and high-performance liquid chromatographyâ€ "electrospray ionisation-mass spectrometry techniques. International J ournal of Mass Spectrometry, 300 (1), 12-20.

SolarByTheWatt.com. (2009). Solar land area efficiency or how many acres per MW, KWp per acre. Solar land area efficiency or how many acres per MW, KWp per acre, 2011 (October 10).

Sreedharan, E. (2009, May 20). Restrict Yamuna with walls and develop low-lying areas: Metro Chief. Restrict Yamuna with walls and develop low-lying areas: Metro Chief.

Sreenivasan, V. (2008). An integrated framework for analysis of water supply in a developing city: Chennai, India. An integrated framework for analysis of water supply in a developing city: Chennai, India.

Srivastava, S., \& Mukherji, D. (2005). Emerging Cityscapes and Environmental Issues. Economic and Political Weekly, 40(36), 3905-3909.

Swain, A. (1998). Fight for the last drop: Inter-state river disputes in India. Contemporary South Asia, 7 (2), 167180.

Tiwari, G. (2002). Meeting the Challenge of Socioeconomic Diversity in Cities, a Case Study of Delhi, India. Cities, 19(2), 95-103.

Tiwari, G. (2003). Transport and land-use policies in Delhi. Bulletin of the World Health Organisation, 81(6), 444-450.

TNN (2011, J uly 20). Delhi gets water share after truce with Haryana. The Times of India, Delhi.

Vance, C., \& Hedel, R. (2007). The impact of urban form on automobile travel: disentangling causation from correlation. Transportation, 34, 575-588.

M.o.W. (2002). National Water Policy. National Water Policy.

Wentz, E. A., Nelson, D., Rahman, A., Stefanov, W. L., \& Roy, S. S. (2008). Expert system classification of urban land use/ cover for Delhi, India. International J ournal of Remote Sensing, 29(15), 4405-4427.

Yu, X. J ., \& Ng, C. N. (2007). Spatial and temporal dynamics of urban sprawl along two urban- rural transects: A case study of Guangzhou, China. Landscape and Urban Planning, 79, 96-109. 


\section{INDIAN INSTITUTE FOR HUMAN SETTLEMENTS}

IIHS aims to establish India's first privately funded and managed National Innovation University focused on the challenges and opportunities of urbanisation in all its aspects.

The University is intended to be a globally ranked institution.

The IIHS University will host an integrated programme of quality campus based education and research, practical training for working professionals, distance and blended learning, and a whole array of consultancy services. The University will have a strong interdisciplinary orientation, incorporating both theory and praxis.

The Academic Programme will consist of globally benchmarked Bachelors, Masters and Doctoral Degrees in Urban Practice based on a wide set of disciplines and practice areas central to India's urban transformation. The Masters and Undergraduate programmes of the University will provide a deep understanding of a wide range of topics including the economic drivers of urbanisation, urban planning, the physical infrastructure, transportation systems, the social infrastructure and social justice, land and housing, public safety and disaster management, the environment and sustainability, and law and urban governance.

The applied research programme will help create a new generation of interdisciplinary researchers and a corpus of relevant India-centric knowledge.

IIHS's deep commitment to the process of social transformation in India by providing educational opportunities to deserving learners irrespective of economic and social status, gender, age or disability. 
